\title{
PREDICTING CHANGES OF THE STATE OF A BRIDGE REINFORCED WITH CONCRETE SUPERSTRUCTURES IN VIEW OF OPERATIONAL CHANGES
}

\author{
Pavlo OVCHYNNYKOV ${ }^{1}$, Olha DUBINCHYK ${ }^{1}$, Oleksii TIUTKIN ${ }^{1}$, \\ Vitalii KILDIEIEV ${ }^{1}$, Volodymyr SEDIN ${ }^{2}$, Kateryna BIKUS ${ }^{2}$ \\ ${ }^{1}$ Dep. "Bridges and Tunnels", Dnipro National University of Railway Transport named \\ after Academician V. Lazaryan \\ ${ }^{2}$ Dep. "Basement and Foundations", Prydniprovska State Academy of Civil \\ Engineering and Architecture
}

\begin{abstract}
To solve the problem of predicting the service life of superstructures, this work proposes the basis and methodological developments of creep theory with increasing loads as well as regression analysis of the results of laboratory experiments. The main limitation in terms of reinforcement is corrosion in the concrete cracks, which was determined during laboratory experiments. Based on the results, the approximate analytical dependences concerning reinforcement corrosion depth change over time at a constant value of crack width were selected. The paper substantiates the validity of the analytical dependences as a result of regression analysis; it proposes formulae for determining the corrosion rate of rebars in reinforced concrete superstructures. The obtained analytical dependences allowed for the developing of a process for predicting changes to the state of the superstructure in light of operational changes.
\end{abstract}

Keywords: bridge, superstructure, reinforced concrete, reinforcement, concrete creep, cracks, corrosion depth

\footnotetext{
${ }^{1}$ Corresponding author: Dep. "Bridges and Tunnels", Dnipro National University of Railway Transport named after Academician V. Lazaryan, Lazaryanst. 2, Dnipro, Ukraine, 49010, e-mail: pavlovchinnikov@gmail.com, tel.+380994521502,+380982398380
} 


\section{INTRODUCTION}

Railway transport is the most important integrated transport system in Ukraine, providing non-stop freight and passenger transportation all year round. The railroads provide about half of the total freight turnover and more than one-third of passenger traffic in the country. Thus, the state of engineering structures is of great importance to ensure the safety and continuity of train traffic.

Improving the reliability and durability of engineering structures is one of the most important issues, which is also required for the safe and continuous operation of the roads. The state of engineering structures affects the carrying and traffic capacity of the railway.

Currently, a large number of bridges, pipe-culverts, and tunnels, built in different periods and, depending on their defects, having different load-bearing capacities, are used for the railways. Having inspected the bridge structures, one can judge the stress-state of reinforced concrete superstructures in view of changes in working conditions and the possibilities for its further operation as well as providing corrective measures to eliminate defects and damages.

Bridges, tunnels, and pipe-culverts are the most important, complex, and expensive elements of traffic. Their total cost is around $17 \%$ of the value of the fixed assets of track facilities. Long-term experience of the operation of reinforced concrete bridge superstructures shows that, in real terms, in the supporting structures, the starting design parameters change and in many cases, these changes lead to various damages.

Changes in operating conditions during the period of structure operation are envisaged in regulations for the design of reinforced concrete superstructures. In particular, to limit displacement of the track centreline with respect to the bridge axis to within $5 \mathrm{~cm}$, and ensure the thickness of the ballast layer can be up to 50 $\mathrm{cm}$. However, in real conditions, marked parameters exceed permissible ones. These deviations usually lead to an increase in structural deflection and the appearance of inadmissible cracks. As a result, reinforcement corrosion develops at the locations of the appearance of the cracks.

\section{PURPOSE}

In operating conditions, the stress-strain state of the bridge structure at the time of the survey conducted in order to determine the service life is different from the estimations assumed at the design stage. For reliable service life prediction, it is necessary to know the background of loading as well as the variability of the ageing process in the material within its remaining operating life [1].

Thus, there arises a problem of "creep", which should be considered with heavier loads. The correct solution is largely determined by the reliability of predictions 
for equations expressing the mechanical condition of the materials. These equations are phenomenological dependencies, yielded based on laboratory experiments with the simplest standard loading modes and subsequent generalizations using working hypotheses.

In terms of artificial structures for railways, service life is the main durability criterion [2]. Bridges are the most durable and responsible transport structures, so their repair or replacement is carried out in the event of the slightest real security threat to train movements, or any other service failure [3]. Therefore, solving scientific and technical problems of service life prediction for superstructures in the context of both defects and damage accumulation [4], that is, taking into account changes in operating conditions, is of primary importance.

\section{METHODOLOGY}

Using pre-conditions and assumptions in the development of a methodology of calculation for reinforced concrete structures, I. M. Bondarenko presented complete relative deformations of concrete $[5,6]$ as

$$
\varepsilon\left(t, t_{0}\right)=\varepsilon_{s m}\left(t, t_{0}\right)+\frac{S_{m}\left[\frac{\sigma\left(t_{0}\right)}{R_{b}\left(t_{0}\right)}\right]}{E_{b}\left(t_{0}\right)}+S_{n}\left[\frac{\sigma\left(t_{0}\right)}{R_{b}\left(t_{0}\right)}\right] C_{t_{i}}^{*}\left(t, t_{0}\right)
$$

where:

$S_{m}$ and $S_{n}$ - nonlinearity and stress functions corresponding to partial deformations;

$R_{b}\left(t_{0}\right)$ - design resistance of concrete to axial compression;

$\sigma\left(t_{0}\right)$ - stress in concrete at the beginning of structure operation;

$C_{t_{i}}^{*}\left(t, t_{0}\right)$ - unit deformation of creep;

$\varepsilon_{s m}\left(t, t_{0}\right)$ - limit strain of concrete shrinkage.

In accordance with $[3,6]$ :

$$
\begin{gathered}
\varepsilon\left(t, t_{0}\right)=\varepsilon_{s m}\left(t_{0}\right) F_{y}\left(t, t_{0}\right) ; \\
\frac{1}{E_{b}(t)}=\frac{F_{m}(t)}{E_{b}^{0}(\infty)}
\end{gathered}
$$




$$
\begin{gathered}
C_{t_{i}}^{*}\left(t, t_{0}\right)=\frac{1}{E_{b}\left(t_{0}\right)}-\frac{1}{E_{b}(t)}+F_{n}(t) f\left(t, t_{0}\right) C_{\mathrm{lim}, i} ; \\
R_{b}\left(t_{0}\right)=F_{R}\left(t_{0}\right) \beta_{R} \eta_{R} R_{b}^{c} ; \\
\varepsilon_{s m}\left(t_{0}\right)=b_{0} B^{\frac{3}{2}}[F(r, \theta)]^{b^{3}} \\
E_{b}(\infty)=\left[E_{b}\left(t_{0}\right)\right][f(\theta) f(r)] \beta_{E} ; \\
C_{\lim , i}=b_{0} B\left[R_{b}\left(t_{0}\right)\right]^{b_{1}}\left[f\left(\frac{R_{b t}}{R}\right)\right][F(r, \theta)] \beta_{c} k_{b} .
\end{gathered}
$$

In the above dependencies

$F_{y}, F_{m}, F_{R}, F_{n}$ - functions of age for shrink, instantaneous elastic deformations, strength and corresponding creep;

$\beta_{R}, \beta_{E}, \beta_{c}$ - temperature coefficients of resistance, elasticity, and creep;

$k_{b}$ - vibrato-creep factor;

$t_{0}$ - beginning of structure operation;

$t$ - structure survey time;

$E_{b}$ - modulus of concrete elasticity;

$C_{\lim , i}-$ limiting unit strain of creep;

$f(\theta)$ - function that takes into account massiveness of elements;

$f(r)$ - function that takes into account the effect of humidity conditions;

$r, \theta$ - Student's criterion;

$F(r, \theta)$ - function that takes into account the combined effect of humidity conditions and massiveness of elements;

$R_{b t}$ - design resistance of concrete to axial tension;

$R$ - concrete strength after 28 days.

The presentation of mechanical condition as (3.1) ... (3.8) is handy for practical calculations. It should be noted that equation (3.1) describes the material state during the simplest loading of the element with constant stress over time. For describing the deformation at increasing changes of modes of loading, one can create an independent equation of mechanical state. However, this method will lead to cumbersome problem-solving and is unacceptable for engineering calculations. Therefore, assuming that the swelling and shrinkage deformations 
do not depend on active stress and that instantaneous elastic deformations do not depend on mode and duration of loading, and further that creep at the time of loading start is zero, for full stresses at discrete load increases, it can be written:

$$
\varepsilon\left(t, t_{0}\right)=\varepsilon_{n}\left(t, t_{0}\right) \sum_{i=0}^{N} \Delta \varepsilon_{n}\left(t_{i}, \tau_{i}\right)
$$

or in the case of continuous increase of the loading

$$
\varepsilon\left(t, t_{0}\right)=\varepsilon_{n}\left(t, t_{0}\right)+\int_{t_{0}}^{t} \frac{\partial \varepsilon_{n}}{\partial \tau} \partial \tau
$$

In view of the given relationships, (3.1) is represented as

$$
\varepsilon\left(t, t_{0}\right)=\varepsilon_{s}\left(t, t_{0}\right)+\frac{S_{m}\left[\frac{\sigma(t)}{R(t)}\right]}{E_{m}(t)}+\int_{t_{0}}^{t} S_{n}\left[\frac{\sigma(\tau)}{R(\tau)}\right] \frac{\partial}{\partial \tau} c_{t_{i}} d \tau
$$

Thus, to predict the residual service life of the superstructure, adjusted for the mechanical state of concrete, it is necessary to know the magnitude of shrinkage, modules of creep and elasticity, and change of the loading level in the compressed concrete area up to the time of construction survey.

During the operation of concrete bridge structures, stress levels in the compressed concrete area increase leading to an infringement of the linear law of stress variations and creep deformation. For this case in study [4-6], a fairly simple analytical expression was proposed

$$
C_{t}\left(t, t_{0}, \eta\right)=C_{t}\left(t, t_{0}\right)+v_{0} \eta^{m} C_{t}\left(t, t_{0}\right) e^{-\left[s C_{t}\left(t, t_{0}\right)\right]}
$$

where:

$C_{t}\left(t, t_{0}\right)$ - a measure of simple creep, not depending on the relative level of stresses;

$\eta ; v_{0}, m, s$ - numerical parameters.

In the study [5], the illustrated dependences were used for describing the set of curves of concrete creep in the elements working in natural climatic conditions at increasing loads over time. They are typical for operating conditions of bridge superstructures.

For experimental evaluation, concrete samples with cross-sectional dimensions of $10 \times 10 \mathrm{~cm}$ and a height of $40 \mathrm{~cm}$ were manufactured in metal moulds. Loading of samples at 28 days was carried out on a spring-hydraulic device HP/200 
constructed at CSRIC (Central Scientific Research Institute of Construction). The loaded samples were kept in natural conditions. After the onset of the stabilization period of creep growth, the stress level increased gradually within $0,1 R_{b}$.

\section{FINDINGS}

Test results are shown in Figure 1. Theoretical curves plotted (3.11) using mathematical models of predicting the mechanical properties of concrete according to dependencies (3.2) ... (3.8) and (3.12) are also presented.

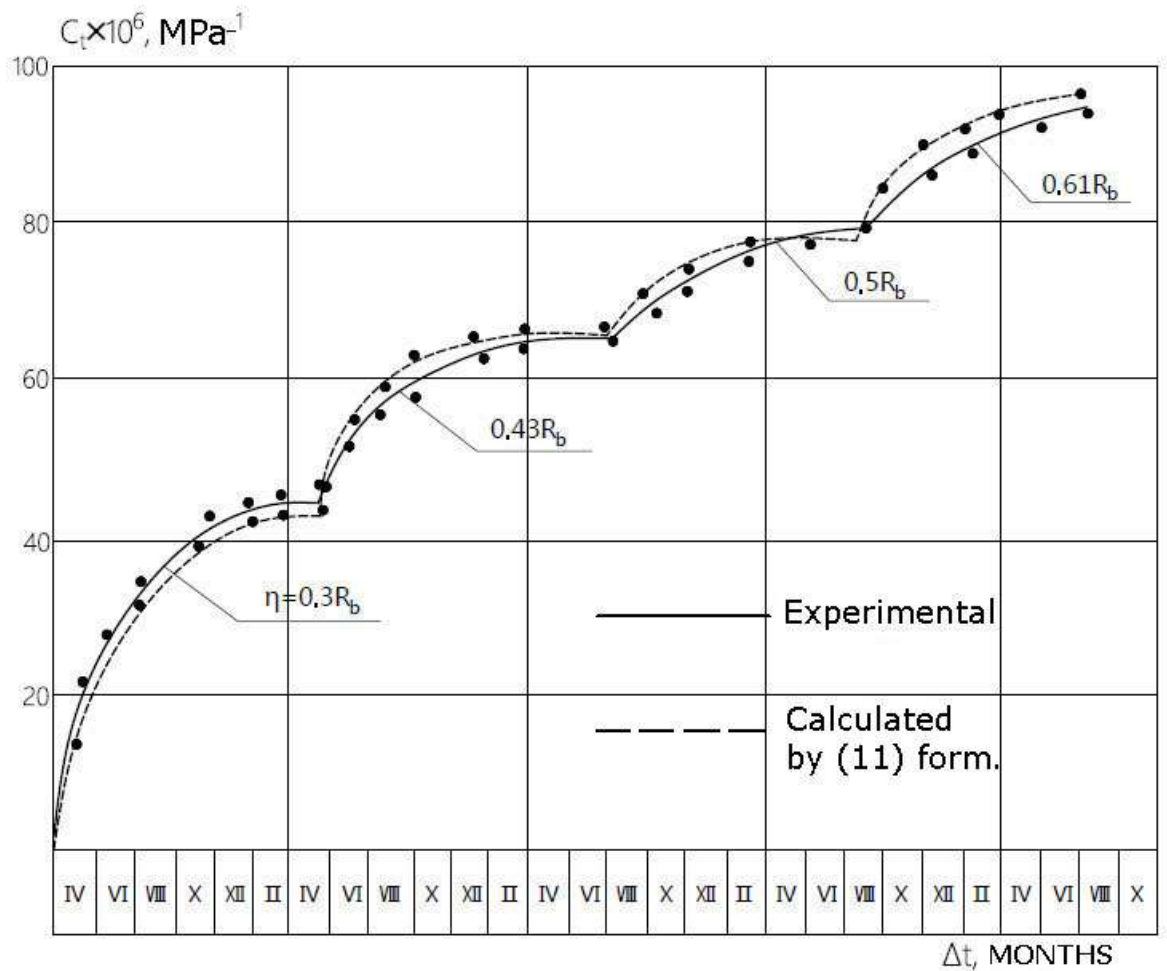

Fig. 1. Concrete creep geometry at increasing stresses over time in natural climatic conditions

As shown in Figure 1, dependence (3.11) with the proposed methods for evaluating the numerical parameters of deformations satisfactorily describes the process of deformation growth at increasing loadings. The obtained results can be used in predicting superstructure residual service life for cases where, in the operation of a process span, stress levels in the structure increase due to the introduction of heavier live loads, increasing of ballast depth, and so on. 
Cracks are the most common form of damage in reinforced concrete bridge superstructures. In standard reinforced concrete structures, the appearance of cracks in tensile zones at stresses that are higher than the design strength of the concrete is an unavoidable process; it is envisaged at the design stage with restriction of crack growth of $0.2 \mathrm{~mm}$. The belief is that at such a growth level, there is no intensive moisture penetration into the reinforcement so, it will not corrode profusely and the operational capability of the construction will be maintained.

In pre-stressed concrete structures with reinforcement in the form of wire strands, individual wires or cables, cracks in the concrete are very dangerous. Moisture penetration through these cracks can lead to rapid corrosion, reducing the reinforcing steel cross-section due to the small diameter of the wire.

The most typical types of cracks occurring in reinforced concrete bridge superstructures are: a) shrink; b) diagonal; c) longitudinal in the intersection between the ballast slab and beam wall; g) longitudinal in the pre-compressed zones; d) transverse in the ballast slab; e) transverse in the lower stretched zones of pre-stressed superstructures; g) horizontal on the end sections of superstructures [6].

A very important property of the crack is the stability of its opening; many cracks in concrete "breathe" under the impact of alternating thermal and humidity strains and changes of external load, that is to say, their opening size varies during the structure's operation. Compared with stable varieties, such cracks are more dangerous with regard to reinforcement corrosion as protective deposits degrade periodically $[7,8]$.

Cracks of corrosive origin, regardless of their growth, are dangerous: they indicate both the aggressiveness of the environment in which concrete fails in its protective function in relation to reinforcement and a deep, continuous corrosion process.

Corrosion cracks are formed in the protective layer due to the high tensile stresses in concrete, developed due to the accumulation of rust on the surface of the rebar if conditions are favourable for corrosion. Corrosion of reinforcement at the original monolithic layer can be caused by many factors: high concrete porosity, carbonization, stray currents impact, and corrosive gases [7,9].

Due to the nature of corrosion damage, it can be either a) non-uniform; b) isolated; c) pitting; d) spot; e) penetrative; f) threadlike; g) inter-granular; h) selective.

As a result of the combined impact of corrosion and mechanical factors, the following phenomena may appear:

a) fretting corrosion - corrosion at oscillatory moving areas under the corrosive environment effect; 
b) corrosion cracking - corrosion of metal under the simultaneous effects of corrosive environment and external or internal mechanical tensile stresses with the formation of trans-granular and inter-granular cracks;

c) corrosion fatigue - reducing the metal fatigue limit under the simultaneous effect of cyclic tensile stresses and corrosive environments;

d) corrosion brittleness - property of a metal as a result of corrosion.

By the very nature of the corrosion process, metal can be disintegrated by chemical and electrochemical mechanisms. Concrete transport structures are affected by electrochemical corrosion while chemical corrosion is rarely seen.

Corrosion of reinforcement steel is determined by both internal and external factors. The internal factors include the chemical composition and structure of the metal, mechanical stresses, and the presence of impurities; external factors are the presence of cracks, the aggressiveness of the environment, motion of water, ambient temperature, amongst others.

In the presence of cracks in concrete galvanic macro-couple on steel reinforcement, the following may arise; anode areas - reinforcement in the crack zone; cathode areas - the point where the adhesive strength of concrete and steel is not broken. The area of anode sections depends on the value of crack-openings and the diameter of reinforcement. Due to the small size of the anode areas in comparison with cathode ones, and the low electrical resistance of moistened concrete, the work of such a corrosive couple runs very intensively. Cracks in the concrete dramatically shift the stationary potential of reinforcement in the negative direction and cause intense corrosion.

Corrosion of reinforcements, with cracks in concrete under normal atmospheric conditions, see their continuous growth decreasing with time, which can be explained by the self-compaction of cracks. Most self-compaction occurs in thin cracks (opening up to $0.2 \mathrm{~mm}$ ) due to the crystallization of $\mathrm{Ca}(\mathrm{OH})_{2}$, calcium carbonate, and calcium hydroxide deposition. In cracks with larger growth, this deceleration may not occur.

One of the main causes of failure of reinforced concrete bridge superstructures is the reduction of the area of working reinforcement due to corrosion or threat of intensive development of this process.

In operating reinforced concrete bridge structures, it is impossible to determine visually how intense this corrosion process is and so, it must be established by an indirect method, one of which is to determine the depth of reinforcement corrosion by observing the crack width.

Figure 2 shows a graph derived from data of reinforcement corrosion depending on the crack width in concrete.

As seen in Figure 2, the likelihood of corrosion processes acting on reinforcement in crack areas in concrete is higher the greater the opening. In order to use these 
graphics in analytical calculations, it is necessary to obtain analytical dependence which would include three variables: the crack width, years of construction operation, and depth of reinforcement corrosion.

For the graphs, approximate dependences were selected using the least-squares method (Fig. 2). For function approximation $f(x)$ on a segment $[a, b]$ by polynomials, by its special values specified at discrete points $a \leq x_{0}, x_{1}, \ldots, x_{n} \leq b$, the degree of the polynomial was chosen according to the number of interpolation nodes so that an approximating polynomial is uniquely determined.

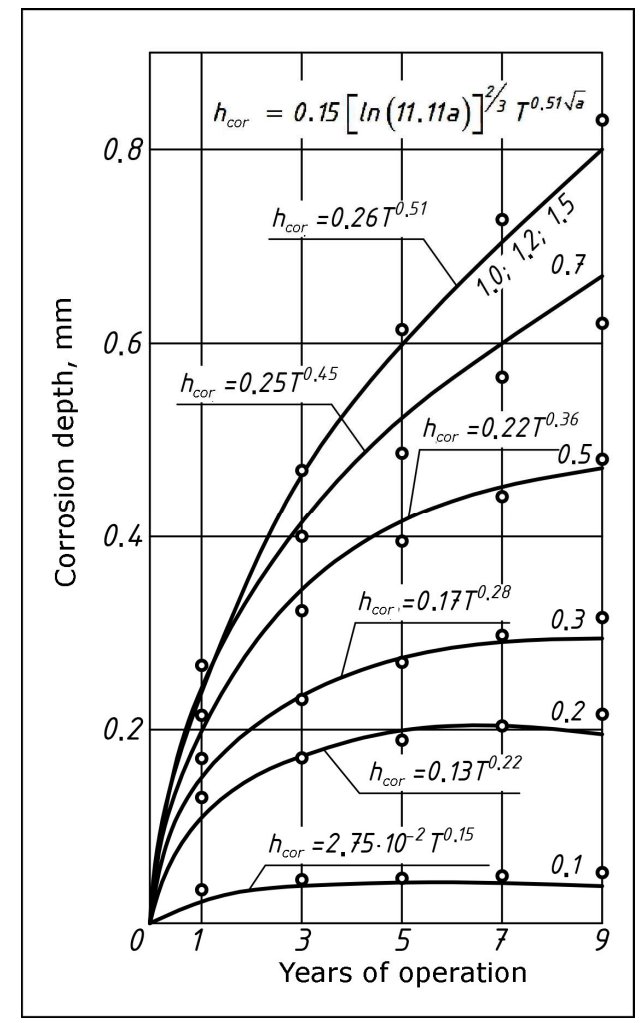

Fig. 2. Development of reinforcement corrosion in cracks of reinforced concrete (The figures on curves - crack opening in millimetres; $\mathrm{o}-$ data by approximated formulas)

Power functions describe the above-mentioned graphics most reliably.

$$
h_{\text {cor }}=c T^{n}
$$

where:

$c, n$-parameters selected according to the results of the experimental data. 
In order to obtain single dependence for the argument and index of yielded functions, home graphics were constructed and also approximated (Fig. 3). The graph of arguments is best described with a logarithmic function and the graph of index is described with a power function. Thus, the dependence to describe the depth of the corrosion process, depending on the crack width and service life, was obtained:

$$
h_{c o r}=0,15[\ln (11,11 \cdot a)]^{2 / 3} T^{0,51 \sqrt{a}}
$$

where:

$a$ - the crack width, mm;

$T$ - years of construction operation.

Table 1 shows selected results of calculations obtained by the formula (4.2).

Table 1. Reinforcement corrosion depth, mm

\begin{tabular}{|c|c|c|c|c|c|c|c|}
\hline \multirow{2}{*}{ Crack width a, mm } & \multicolumn{7}{|c|}{ Years of operation } \\
\cline { 2 - 8 } & 1 & 5 & 10 & 20 & 40 & 50 & 100 \\
\hline 0.1 & 0.033 & 0.043 & 0.048 & 0.053 & 0.060 & 0.062 & 0.089 \\
\hline 0.2 & 0.129 & 0.185 & 0.216 & 0.252 & 0.294 & 0.309 & 0.361 \\
\hline 0.3 & 0.170 & 0.264 & 0.319 & 0.385 & 0.466 & 0.495 & 0.599 \\
\hline 0.4 & 0.196 & 0.326 & 0.405 & 0.505 & 0.28 & 0.674 & 0.840 \\
\hline 0.5 & 0.215 & 0.379 & 0.485 & 0.620 & 0.792 & 0.857 & 1.094 \\
\hline 0.6 & 0.230 & 0.429 & 0.561 & 0.733 & 0.959 & 1.046 & 1.368 \\
\hline 0.7 & 0.322 & 0.475 & 0.634 & 0.848 & 1.133 & 1.244 & 1.662 \\
\hline 0.8 & 0.252 & 0.519 & 0.707 & 0.964 & 1.314 & 1.452 & 1.980 \\
\hline 0.9 & 0.261 & 0.561 & 0.779 & 1.083 & 1.504 & 1.672 & 2.323 \\
\hline 1.0 & 0.269 & 0.603 & 0.852 & 1.205 & 1.704 & 1.905 & 2.695 \\
\hline
\end{tabular}

The results of test calculations by obtained formulas are presented (as points) in Fig. 3. These points have been included in $95 \%$ of confidence region limits, indicating the reliability of the chosen formula. 
144 Pavlo OVCHYNNYKOV, Olha DUBINCHYK, Oleksii TIUTKIN, Vitalii KILDIEIEV, Volodymyr SEDIN, Kateryna BIKUS

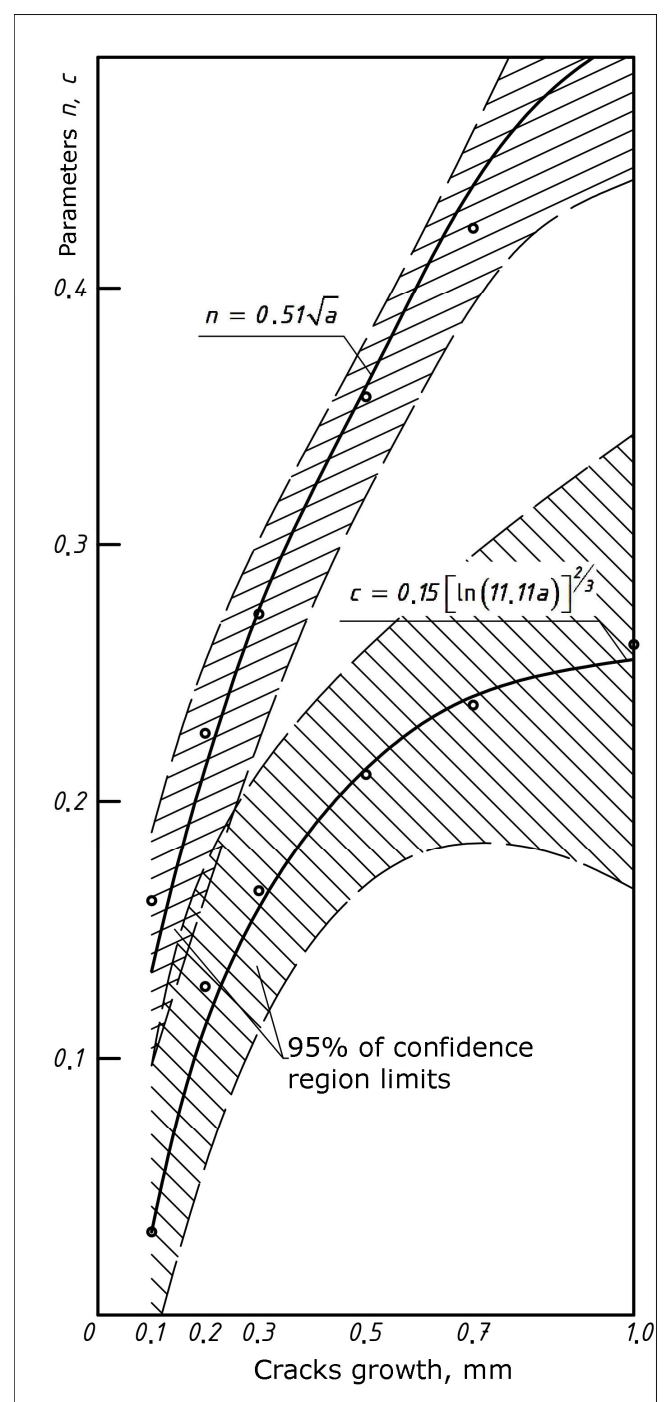

Fig 3. Regression equation factor curve

The rate of corrosion is in direct proportion to the crack width: the larger the crack width, the faster the corrosion process. Using the formula (4.2), the dependence for determining the corrosion process rate in the rebar was obtained

$$
V_{c o r}=0,08 \sqrt{a} \cdot[\ln (11,11 a)]^{2 / 3} \cdot T^{0,51 \sqrt{a}-1}
$$


Calculation results are given in Table 2.

Table 2. The corrosion rate of rebars in concrete superstructures, $\mathrm{mm} / \mathrm{year}$

\begin{tabular}{|c|c|c|c|c|c|c|c|}
\hline \multirow{2}{*}{ The crack width, mm } & \multicolumn{7}{|c|}{ Years of operation } \\
\cline { 2 - 8 } & 1 & 5 & 10 & 20 & 30 & 40 & 50 \\
\hline 0.1 & 0.025 & & & & & & \\
\hline 0.2 & 0.12 & 0.025 & & & & & \\
\hline 0.3 & 0.15 & 0.016 & 0.009 & 0.006 & 0.004 & 0.0034 & 0.0028 \\
\hline 0.4 & 0.17 & 0.026 & 0.013 & 0.009 & 0.006 & 0.0052 & 0.0044 \\
\hline 0.5 & 0.2 & 0.028 & 0.018 & 0.012 & 0.009 & 0.007 & 0.0064 \\
\hline 0.6 & 0.23 & 0.032 & 0.023 & 0.015 & 0.012 & 0.010 & 0.008 \\
\hline 0.7 & 0.24 & 0.043 & 0.027 & 0.019 & 0.015 & 0.012 & 0.0108 \\
\hline 0.8 & 0.25 & 0.050 & 0.032 & 0.023 & 0.018 & 0.015 & 0.013 \\
\hline 0.9 & 0.26 & 0.056 & 0.038 & 0.028 & 0.022 & 0.018 & 0.016 \\
\hline 1.0 & 0.27 & 0.064 & 0.044 & 0.032 & 0.026 & 0.022 & 0.019 \\
\hline
\end{tabular}

After inspecting the concrete bridge span, determining the crack width, and defining the depth of corrosion, one can calculate the remaining area of the rebar, which receives the loads

$$
A_{s}^{r e m}=\pi r^{2}-\frac{4}{3} h_{c o r}-\sqrt{r^{2}-\left(r-h_{c o r}\right)^{2}}
$$

where:

$r$ - design radius of working reinforcement in bridge span.

This formula is used when there is no permanent water access to the structure. The reinforcement is in the girder wall and corrosion occurs by the segment. However, very often, there is ingress of moisture to reinforcement located in the slab of a beam, due to cracks and also the poor performance of drainage pipes. In this case, the reinforcement corrosion occurs circularly, and the area of remaining reinforcement is calculated by the formula

$$
A_{s}^{r e m}=\pi\left(r-h_{c o r}\right)^{2}
$$


Table 3 shows the area of reinforcement in the girder wall adjusted for corrosion. Thus, using the data from Tables 1-3, one can clearly and reliably predict the development of the reinforcement corrosion depth, estimating the crack width over time and, using formulas (4.4) ... (4.5), calculate the working area of the rebar which was corroded.

Table 3. The area of reinforcement adjusted for corrosion

\begin{tabular}{|c|c|c|c|c|c|c|c|c|}
\hline \multirow{4}{*}{$\begin{array}{l}\text { Crack } \\
\text { width, } \\
\text { a, mm }\end{array}$} & \multicolumn{8}{|c|}{ Reinforcement diameter $-16 \mathrm{~mm}$} \\
\hline & \multicolumn{8}{|c|}{$A_{s}^{r e m}, \mathrm{~cm} 2$} \\
\hline & \multicolumn{8}{|c|}{ Years of operation } \\
\hline & 0 & 1 & 5 & 10 & 20 & 40 & 50 & 100 \\
\hline 0.1 & 2.0096 & 2.0093 & 2.0091 & 2.0090 & 2.0089 & 2.0088 & 2.0088 & 2.0086 \\
\hline 0.2 & 2.0096 & 2.0071 & 2.0054 & 2.0043 & 2.0029 & 2.0012 & 2.0005 & 1.9982 \\
\hline 0.3 & 2.0096 & 2.0059 & 2.0024 & 2.0001 & 1.9970 & 1.9929 & 1.9913 & 1.9854 \\
\hline 0.4 & 2.0096 & 2.0050 & 1.9998 & 1.9960 & 1.9908 & 1.9836 & 1.9807 & 1.9697 \\
\hline 0.5 & 2.0096 & 2.0043 & 1.9973 & 1.9919 & 1.9841 & 1.9730 & 1.9685 & 1.9507 \\
\hline 0.6 & 2.0096 & 2.0038 & 1.9948 & 1.9876 & 1.9769 & 1.9610 & 1.9545 & 1.9280 \\
\hline 0.7 & 2.0096 & 2.0033 & 1.9924 & 1.9832 & 1.9691 & 1.9476 & 1.9386 & 1.9014 \\
\hline 0.8 & 2.0096 & 2.0029 & 1.9900 & 1.9786 & 1.9607 & 1.9326 & 1.9206 & 1.8705 \\
\hline 0.9 & 2.0096 & 2.0025 & 1.9876 & 2.9738 & 1.9516 & 1.9159 & 1.9005 & 1.8350 \\
\hline 1.0 & 2.0096 & 2.0022 & 1.9851 & 1.9688 & 1.9418 & 1.8975 & 1.8780 & 1.7944 \\
\hline
\end{tabular}

Service life, as a characteristic of durability [10-12], defines reserve of possible operating time of the object from the beginning of its operation to the occurrence of its limit state. The unit of measurement of service life for the concrete bridge spans is time. Service life depletion, i.e. the occurrence of this limit state, is the result of gradual accumulation of various faults and damages, as well as crack propagation $[13,14]$.

In the theory of linear damage accumulation, the $\psi$ function, having a value equal to zero at the start of loading and equalling one at the time of failure, is taken as a measure of damage. It can be represented as 


$$
\psi=\frac{A_{s}-A_{s}^{t}}{A_{s}-A_{s}^{c r c}}
$$

where:

$A_{s}$ - the original area of beam reinforcement, $\mathrm{cm}^{2}$;

$A_{s}{ }^{t}$ - beam reinforcement area at the time of technical diagnostics, $\mathrm{cm}^{2}$;

$A_{s}{ }^{c r c}$ - critical reinforcement area as a result of corrosion, $\mathrm{cm}^{2}$.

At the beginning of operation $A_{s}{ }^{t}=A_{s}, \psi=0$ - no damage, the structure is in a good state.

When $A_{s}{ }^{t}=A_{s}{ }^{c r c}, \psi=1,0$ - the structure is worn out, there is the occurrence of a collapse point.

To determine the critical area of corroded reinforcement, four cases of the stress state of reinforced concrete bridge superstructures were considered.

The $1^{\text {st }}$ case: the neutral axis is in the slab of the beam, the reinforcement is nonpre-stressed.

Area of reinforcement can be determined from the height equation of the compressed concrete area

$$
x=\frac{R_{s} A_{s}-R_{s c} A_{s}^{\prime}}{R_{b} b_{f}^{\prime}}
$$

where:

$R_{s}$ - design strength of non-pre-stressed reinforcement to tensile;

$R_{s c}$ - design strength of non-pre-stressed reinforcement to compression;

$R_{b}$ - design strength of concrete to axial compression;

$b_{f}$ - effective width of the slab of a beam;

$A_{s}$ - area of non-pre-stressed stretched longitudinal reinforcement;

$A_{s}{ }^{\prime}$ - area of non-pre-stressed compressed longitudinal reinforcement.

But, in this equation, there are two unknowns $-x$ and $A_{s}$. To obtain the solution it is necessary to determine $x$ from the condition

$$
M \leq R_{b} b_{f}^{\prime} x\left(h_{0}-0,5 x\right)+R_{s c} A_{s}^{\prime}\left(h_{0}-a_{s}^{\prime}\right)
$$

where

$h_{o}$ - working height of the beam section;

$a_{s}{ }^{\prime}$ - distance from the centre of gravity of the compressed non-pre-stressed longitudinal reinforcement to the nearest edge of the cross-section. 
The bending moment is calculated according to the findings of the inspection of the bridge span state $[12,14]$. Making the conversion of the formula $(4.8)$, we obtain a square equation

$$
-0,5 R_{b} b_{f}^{\prime} x^{2}+R_{b} b_{f}^{\prime} h_{0} x+R_{s c} A_{s}^{\prime}\left(h_{0}-a_{s}^{\prime}\right)-M=0
$$

the roots of which will be the following expression

$$
x_{1,2}=\frac{-R_{b} b_{f}^{\prime} h_{0} \pm \sqrt{\left(R_{b} b_{f}^{\prime} h_{0}\right)^{2}+2 R_{b} b_{f}^{\prime}\left[R_{s c} A_{s}^{\prime}\left(h_{0}-a_{s}^{\prime}\right)-M\right]}}{-R_{b} b_{f}^{\prime}}
$$

Instead of $x$, we substitute its value (4.7)

$$
\begin{aligned}
& \frac{R_{s} A_{s}-R_{s c} A_{s}^{\prime}}{R_{b} b_{f}^{\prime}}= \\
& =\frac{-R_{b} b_{f}^{\prime} h_{0} \pm \sqrt{\left(R_{b} b_{f}^{\prime} h_{0}\right)^{2}+2 R_{b} b_{f}^{\prime}\left[R_{s c} A_{s}^{\prime}\left(h_{0}-a_{s}^{\prime}\right)-M\right]}}{-R_{b} b_{f}^{\prime}}
\end{aligned}
$$

After converting, we obtain a formula for determining the critical area of reinforcement based on corrosion

$$
\begin{aligned}
& A_{s}^{c r c} \leq \\
& \leq \frac{R_{b} b_{f}^{\prime} h_{0} \pm \sqrt{\left(R_{b} b_{f}^{\prime} h_{0}\right)^{2}+2 R_{b} b_{f}^{\prime}\left[R_{s c} A_{s}^{\prime}\left(h_{0}-a_{s}^{\prime}\right)-M\right]}+R_{s c} A_{s}^{\prime}}{R_{s}}
\end{aligned}
$$

Similarly, we calculate the 2 nd case, when the neutral axis is in the girder wall

$$
x=\frac{R_{s} A_{s}-R_{s c} A_{s}^{\prime}-R_{b}\left(b_{f}^{\prime}-b\right) h_{f}^{\prime}}{R_{b} b}
$$

where

$b$ - width of girder wall;

$h_{f}^{\prime}$ - effective thickness of the slab of a ballast tank. 


$$
\begin{aligned}
& M \leq R_{b} b x\left(h_{0}-0,5 x\right)+R_{b}\left(b_{f}^{\prime}-b\right) h_{f}^{\prime}\left(h_{0}-0,5 h_{f}^{\prime}\right)+ \\
& +R_{s c} A_{s}^{\prime}\left(h_{0}-a_{s}^{\prime}\right) \\
& +\frac{A_{s}^{c r c} \leq \frac{R_{b} b h_{0} \pm \sqrt{\left(R_{b} b h_{0}\right)^{2}+2 R_{b} b\left[R_{b} h_{f}^{\prime} \times\right.}}{\left.\left(b_{f}^{\prime}-b\right)\left(h_{0}-0,5 h_{f}^{\prime}\right)+R_{s c} A_{s}^{\prime}\left(h_{0}-a_{s}^{\prime}\right)-M\right]}+}{{ }^{+R_{s c} A_{s}^{\prime}+R_{b}\left(b_{f}^{\prime}-b\right) h_{f}^{\prime}}} \\
& R_{s}
\end{aligned}
$$

The 3D case: the neutral axis is in the slab of the beam and rebars are pre-stressed.

$$
x=\frac{R_{p} A_{p}+R_{s} A_{s}-R_{s c} A_{s}^{\prime}-\sigma_{p c} A_{p}^{\prime}}{R_{b} b_{f}^{\prime}}
$$

where

$R_{p}$ - design strength of pre-stressed reinforcement to tensile;

$\sigma_{p c}-$ residual strength in pre-stressed reinforcement, located in compression zone;

$A_{p}$ - area of pre-stressed stretched longitudinal reinforcement; $A_{p}{ }^{\prime}$ - area of pre-stressed compressed longitudinal reinforcement.

$$
M \leq R_{b} b_{f}^{\prime} x\left(h_{0}-0,5 x\right)+R_{s c} A_{s}^{\prime}\left(h_{01}-a_{s}^{\prime}\right)+\sigma_{p c} A_{p}^{\prime}\left(h_{0}-a_{p}^{\prime}\right)
$$

where

$h_{01}$ - distance from the top of the beam to the centre of gravity in non-pre-stressed stretched longitudinal reinforcement;

$a_{p}^{\prime}$ - distance from the centre of gravity of pre-stressed compressed longitudinal reinforcement to the nearest edge of the cross-section. 


$$
\begin{aligned}
& A_{p}^{c r c} \leq R_{b} b_{f}^{\prime} h_{0} / R_{p} \pm \sqrt{\left(R_{b} b_{f}^{\prime} h_{0}\right)^{2}+2 R_{b} b_{f}^{\prime}\left[R_{s c} A_{s}^{\prime}\left(h_{01}-a_{s}^{\prime}\right)+\right.} \rightarrow \\
& \left.\rightarrow+\sigma_{p c} A_{p}^{\prime}\left(h_{0}-a_{p}^{\prime}\right)-M\right] / R_{p}- \\
& -R_{s} A_{s} / R_{p}+R_{s c} A_{s}^{\prime} / R_{p}+\sigma_{p c} A_{p}^{\prime} / R_{p}
\end{aligned}
$$

The 4th case: the neutral axis is in the girder wall, reinforcement is pre-stressed.

$$
\begin{aligned}
x= & \frac{R_{p} A_{p}+R_{s} A_{s}-R_{s c} A_{s}^{\prime}-\sigma_{p c} A_{p}^{\prime}-R_{b}\left(b_{f}^{\prime}-b\right) h_{f}^{\prime}}{R_{b} b} \\
M & \leq R_{b} b x\left(h_{0}-0,5 x\right)+R_{b}\left(b_{f}^{\prime}-b\right) h_{f}^{\prime}\left(h_{0} 0,5 h_{f}^{\prime}\right)+ \\
+ & R_{s c} A_{s}^{\prime}\left(h_{01}-a_{s}^{\prime}\right)+\sigma_{p c} A_{p}^{\prime}\left(h_{0}-a_{p}^{\prime}\right) \\
& A_{p}^{c r c} \leq R_{b} b h_{0} / R_{p} \pm \sqrt{\left(R_{b} b h_{0}\right)^{2}+2 R_{b} b\left[R_{b} h_{f}^{\prime} \times\right.} \\
& \rightarrow \frac{}{\times\left(b_{f}^{\prime}-b\right) \times\left(h_{0}-0,5 h_{f}^{\prime}\right)+R_{s c} A_{s}^{\prime}\left(h_{01}-a_{s}^{\prime}\right)+} \rightarrow \\
& \rightarrow \frac{\left.+\sigma_{p c} A_{p}^{\prime}\left(h_{0}-a_{p}^{\prime}\right)-M\right] / R_{p}-R_{s} A_{s} / R_{p}+}{+R_{s c} A_{s}^{\prime} / R_{p}+\sigma_{p c} A_{p}^{\prime} / R_{p}+R_{b}\left(b_{f}^{\prime}-b\right) h_{f}^{\prime} / R_{p}}
\end{aligned}
$$

Table 4 shows the standard values of $\psi[15]$.

Table 4. Standard values of the measure of damage accumulation

\begin{tabular}{|l|l|l|l|l|l|l|l|l|}
\hline $\begin{array}{l}\text { Probability of non- } \\
\text { failure, } \mathrm{P}(\psi)\end{array}$ & 0.999 & 0.998 & 0.995 & 0.985 & 0.958 & 0.897 & 0.794 & 0.641 \\
\hline Value of damage, $\psi$ & 0.35 & 0.40 & 0.45 & 0.50 & 0.55 & 0.60 & 0.65 & 0.70 \\
\hline
\end{tabular}

With the data in Table 4 and by using the value of damage accumulation $\psi$, it is possible to assess the level of reliability of the superstructure on the criterion of reinforcement corrosion in the presence of cracks in the structure as well as to argue objectively about the actual state of the superstructure. The main element in solving this problem is to assign a level of reliability $P(\psi)$. 
The occurrence of the limit state by conditions of reinforcement endurance is associated with sufficiently high material costs and poses a risk to human life, therefore, the reliability level should not be lower than 0.95 .

\section{ORIGINALITY AND PRACTICAL VALUE}

For the first time, using laboratory experiments, the development of reinforcement corrosion in concrete cracks was determined, together with an assessment of time-varying corrosion depth. Approximated analytical dependences with a high level of confidence (95\%), allow reasonable prediction of the crack width in a reinforced concrete superstructure. This has a significant practical value for bridge superstructure service life prediction in the context of defect and damage accumulation, taking into account changes in operating conditions. Formulas for determining the corrosion rate in the rebar, with the ability to predict the working area of corroded reinforcement, also have a practical value.

\section{CONCLUSIONS}

The conducted complex of theoretical and practical research of reinforced concrete structures (superstructures) with defects and damages in view of operational changes allowed obtaining scientific results in the form of analytical dependences of reinforcement corrosion in the concrete cracks. The depth of reinforcement corrosion and its rate under certain crack widths, which is determined through inspection, can reliably predict the working area of the corroded bar. This leads to the further assessment of changes in the state of reinforced concrete bridge superstructures as a result of operational changes.

\section{REFERENCES}

1. Tingcheng, Y,Chunhua, L, Zhiren, W andRonggui, L 2008. Durability of Prestressed Concrete Structures Suffering from Chloride Ions' Invasion. International Journal of Nonlinear Science, 5, 184-192.

2. Bažant, ZP and Cedolin, L 1991. Stability of Structures: Elastic, Inelastic, Fracture and Damage Theories. Oxford University Press, New York, USA.

3. Ghousson, MA 2014. The Cyclic Loading of Normal Concrete in a Specific Stress Range. Jordan Journal of Civil Engineering, 8, 3.

4. Aslani, F and Jowkarmeimandi, R 1996. Stress-strain model for concrete under cyclic loading. Magazine of Concrete Research, 64, 8, 2012, 673-685.

5. Mamazhanov, RK and Kildeeva, OI. Prognozirovaniye polzuchesti betona proletnykh stroeniy mostov pri narastayushchikh nagruzheniyakh [Concrete 
creep predicting of bridge superstructures at increasing loadings]. International Proceedings of TIIRT, issue 226/62, pp. 33-38.

6. Mamazhanov, RK 1993. Veroyatnostnoye prognozirovaniye resursa zhelezobetonnykh proletnykh stroeniy mostov [Probabilistic predicting of the service life of reinforced concrete bridge superstructures]. Tashkent, Fan Publ.

7. Ozcelik, R 2014. Cyclic testing of low-strength plain concrete, Magazine of Concrete Research, 67, 8, 379-390.

8. Saleem, M. Pre-construction Durability Index for Reinforced Concrete Structure // Conference: BEST PAPER AWARD - 3rd International Conference on Civil Engineering, https://www.researchgate.net/publication/273757170_Preconstruction_Durability_Index_for_Reinforced_Concrete_Structure.

9. Mahmoud, $\overline{\mathrm{H}}$ and Zafar, A 2016. Time-Dependent Reliability Analysis of Reinforced-Concrete Bridges Including Deterioration Effects. Geotechnical and Structural Engineering Congress 1354-1366.

10. Instruktsiya po opredeleniyu gruzopodemnosti zhelezobetonnykh balochnykh proletnykh stroyeniy avtodorozhnykh mostov VSN 32-78 [Instructions for determining the carrying capacity of reinforced concrete beam superstructures of highway bridges VSN 32-78.].- Moscow: Transport Publ., 1979.

11. DBN V.2.3-22:2009. Sporudy transportu. Mosty ta truby. Osnovni vymohy proektuvannia [State Building Standards V.2.3-22: 2009. Transport facilities. Bridges and pipes. Main requirements of design]. Kyiv: MinrehionbudUkrainy Publ., 2009.

12. DBN V.2.6:2009. Sporudy transportu, Mosty ta truby. Obstezhennia I vyprobuvannia [State Building Standards. Transport facilities, bridges and pipes. Inspection and testing.]. Kyiv: MinrehionbudUkrainy Publ., 2009.

13. Duchaczek, A and Mańko, Z 2014. Application of the numerical methods to assessment of the fatigue life of steel military bridges. Roads and BridgesDrogiiMosty, 13, 1, 23-32.

14. Dubinchik, OI and Kildieiev, VR 2015. Prohnozuvannia resursu zalizobetonnikh konstruktsii za vytryvalistiu armatury [Service life predicting of concrete constructions by reinforcement endurance]. Zbirnyk naukovykh prats Mosty ta tuneli: teoriia, doslidzhennia, praktyka [Proc. Bridges and Tunnels: Theory, Research, Practice], 7, 13-18.

15. Dubinchik, OI and Kildieiev, VR 2016. Vyznachennja miry nakopychennja ushkodzhenj zaliznychnykh mostiv z urakhuvannjam koroziji armatury [Determination of damages accumulation measure of railway bridges taking into account armature corrosion]. Mosty ta tuneli: teoriia, doslidzhennia, praktyka [Bridges and Tunnels: Theory, Research, Practice], 9, 18-24.

Editor received the manuscript: 24.06 .2019 